Recepción: 20 / 04 / 2017

Aceptación: 20 / 05 / 2017

Publicación: 15 / 07 / 2017

\title{
Diseño de un cd interactivo multimedia como guía virtual con enfoque y criterio de desempeño
}

\author{
Design of a multimedia interactive cd as a virtual guide \\ with a focus and performance criteria
}

Projeto de um multimídia cd interativo como guia virtual para abordar e critérios de desempenho

Juanita I. Guevara-Burgos I juanita.guevarab@ug.edu.ec

Mónica A. Yépez-Mora ${ }^{\mathrm{II}}$ monica.yepezm@ug.edu.ec
Silvia M. Placencia-Ibadango ${ }^{\text {III }}$ silvia.placenciai@ug.edu.ec
Juana Y. Jiménez-Juanazo ${ }^{\mathrm{IV}}$ juanadoblejj@gmail.com

Correspondencia: juanita.guevarab@ug.edu.ec

Magister en Educación Superior; Licenciada en Ciencias de la Educación Especialización Lengua Inglesa y Lingüística; Profesor de Segunda Enseñanza; Universidad de Guayaquil, Guayaquil, Ecuador.

II. Magister en Gerencia Educativa; Ingeniero Comercial; Universidad de Guayaquil, Guayaquil, Ecuador.

III. Magister en Gerencia Educativa; Especialista en Gestión de Procesos Educativos; Profesor de Segunda Enseñanza Especialización Físico Matemáticas; Odontóloga; Licenciada en Ciencias de la Educación mención Físico Matemática; Universidad de Guayaquil, Guayaquil, Ecuador.

Iv. Magister, Universidad de Guayaquil, Guayaquil, Ecuador. 


\section{Resumen}

El presente proyecto se realiza debido a la baja calidad del desempeño escolar causada por la falta del factor socio-afectivo que tiene la escuela de Educación Básica "Enrique López Lazcano" del Cantón Santa Lucia específicamente en el cuarto grado de educación general básica, donde es necesario innovar el estudio mediante un $\mathrm{CD}$ interactivo multimedia, que tiene un periodo de duración de noventa días especialmente para lograr un resultado positivo en la enseñanzaaprendizaje, la cual tiene como finalidad ofrecer una herramienta tecnológica. Después de efectuar una exploración acerca de el bajo rendimiento y la poca atención que los estudiantes que suelen prestar a la forma tradicional de enseñar, obtenemos la conclusión de crear la aplicación educativa para dinamizar y repotenciar el factor socio afectivo de los educandos dentro del salón de clases. El marco teórico se fundamenta en varias fuentes de consulta por medio de las cuales se pudo establecer la fundamentación psicológica, pedagógica, sociológica, tecnológica y la legal, la información de campo en base al problema fue alcanzado a través de encuestas aplicadas a la población, específicamente a docentes y padres de familia, para luego proceder al análisis de resultados y finalmente a la presentación de la propuesta a la población de estudio, que se beneficia en múltiples aspectos, especialmente en cuanto a la enseñanza-aprendizaje.

Palabras Clave: Interactivo; enseñanza; aprendizaje; multimedia; guía virtual 


\begin{abstract}
The present project is due to the low quality of school performance caused by the lack of socioaffective factor that has the "Enrique López Lazcano" Basic Education school in Canton Santa Lucia specifically in the fourth grade of general basic education, where it is It is necessary to innovate the study by means of a multimedia interactive $\mathrm{CD}$, which has a duration of ninety days especially to achieve a positive result in teaching-learning, which has the purpose of offering a technological tool. After conducting an exploration of the low achievement and the lack of attention that students usually give to the traditional way of teaching, we conclude the creation of the educational application to dynamize and repot the socio-affective factor of learners in the classroom. lessons. The theoretical framework is based on several sources of consultation through which it was possible to establish the psychological, pedagogical, sociological, technological and legal basis, field information based on the problem was reached through surveys applied to the population, Specifically to teachers and parents, and then proceed to the analysis of results and finally to the presentation of the proposal to the study population, which benefits in multiple aspects, especially in terms of teaching-learning.
\end{abstract}

Keywords: Interactive; teaching; learning; multimedia; virtual guide. 


\section{Resumo}

Este projeto é realizado devido à má qualidade do desempenho escolar causada pela falta do fator sócio-emocional com a Escola de Educação Básica "Enrique López Lazcano" do cantão Santa Lucia especificamente na quarta série do ensino fundamental, onde é necessário inovar o estudo através de um CD multimédia interactivo, que tem um período de noventa dias de duração, especialmente para alcançar um resultado positivo no ensino e aprendizagem, que tem como objetivo fornecer uma ferramenta tecnológica. Depois de uma exploração do mau desempenho e a falta de atenção que os estudantes que tendem a emprestar para a forma tradicional de ensino, temos a conclusão para criar o aplicativo educacional para energizar e repotenciação parceiro afetivo dos alunos fator no salão classes. O referencial teórico é baseado em diversas fontes de referência através do qual eles poderiam estabelecer o psicológico, pedagógico, base tecnológica e jurídica sociológica, as informações de campo com base no problema foi conseguido através de inquéritos da população, especificamente para professores e pais, e depois prosseguir para a análise dos resultados e, finalmente, apresentar a proposta para a população de estudo, o que beneficia em muitos aspectos, especialmente em termos de ensino e aprendizagem.

Palavras chave: Interativa; ensino; aprendizagem; multimídia; guia virtual. 


\section{Introducción.}

El uso de la tecnología dentro de la educación se ha convertido en una herramienta importante que facilita la enseñanza-aprendizaje en la comunidad educativa.

Las tecnologías han sido conceptualizadas como la unificación al mundo de la informática, las telecomunicaciones y las técnicas para la enseñanza donde sus elementos principales es el factor humano, el equipamiento, las bases, el software conjuntamente con el mecanismo de intercambio de información. (González García, 2015) (Codina, 2004)

Las familias ecuatorianas se están caracterizando por la independencia de sus miembros, en busca de un futuro próspero, el hombre, jefe del hogar, trabaja todo el día y a duras penas le alcanza para llevar el pan a la mesa y donde la mujer, administradora del hogar, se ha visto en la necesidad de buscar oportunidades laborales dejando a sus vástagos expuestos a las amenazas de la sociedad, un vivo ejemplo es la migración de padres o madres viajando a otro lugar comprometiendo a sus familiares e incluso a desconocidos el cuidado de sus hijos. (Marqués, 2000)

En estudios realizados por el INEVAL se afirma que los estudiantes no tienen el soporte familiar para reflejar las diferencias en el comportamiento, autoestima, motivación, actitudes y presentan niveles de ansiedad, los cuales ante la sociedad son identificados como la pérdida de valores, siendo muy pocas las instituciones que reconocen la importancia de querer preservar los valores existentes en las familias ecuatorianas porque a medida que evoluciona la sociedad el desarrollo del país aumenta. (Estevez Lopez, 2005) (Verschueren \& Marcoen, 2002) 
Actualmente en la escuela de educación básica "Enrique López Lazcano" la enseñanzaaprendizaje utiliza la forma tradicional, donde todo lo que se les enseña a los estudiantes del cuarto grado de educación básica está basado en los libros y trabajos investigativos dispuestos en la mayoría por sus maestras.

Los docentes han adquirido nuevas posibilidades para el desarrollo de sus prácticas por medio de la integración de las nuevas tecnologías, como un recurso más en el proceso de enseñanzaaprendizaje, que permite incentivar en el alumno la interacción, diversificación de información y el auto aprendizaje, a través de la colaboración entre el grupo estudiantil con la experiencia que cada uno aporta y el conocimiento del mismo. Las guías virtuales con enfoque con criterio de desempeño facilitan el aprendizaje de manera activa al aportar con desarrolladas posibilidades de exploración que generan nuevos conocimientos.

La indagación realizada sobres el presente proyecto se desarrolló en base de las necesidades y problemas observados en la institución educativa es así que nació como una alternativa innovadora que pretende dar un nuevo enfoque a la educación y en especial a la enseñanza aprendizaje de la asignatura de estudios sociales con el uso de la tecnología, es por esto que se propuso diseñar e implementar un CD interactivo multimedia. Con el objetivo de optimizar y hacer una clase más dinámica, mejorar la atención del estudiante con eficiencia y eficacia y por ende brindar una buena educación a los estudiantes.

Los beneficiarios directos de la presente investigación son los estudiantes ya que ellos expresaran aptitudes positivas para el desarrollo integral y cognitivo, los docentes lograran dominar el grupo estudiantil y los padres de familia podrán guiar a sus hijos mediante el CD interactivo multimedia como guía virtual con enfoque con criterio de desempeño, dentro y fuera de la 
Institución los cuales podrán mantener una comunicación fluida con sus hijos y los docentes, buscando juntos soluciones para lograr una buena calidad de desempeño escolar y el bienestar de los estudiantes.

Contribuyendo con el proceso enseñanza aprendizaje mediante el resultado del estudio de las conductas afectivas las cuales darán pautas para nuevas soluciones a los problemas que presenta la sociedad, teniendo como resultado una sociedad comunicativa, el individuo al sentirse parte de la sociedad le permitirá desarrollarse integralmente sin obstáculo alguno esto se lograra mediante el CD interactivo multimedia como guía virtual con enfoque con criterio de desempeño.

La propuesta del presente trabajo investigativo es un aporte pedagógico para la educación del país, sirve para la disminución en gran porcentaje las dificultades de aprendizaje del niño, elevar el estado de ánimo y la autoestima en los educandos, preparándolos para que dentro de la sociedad que los rodea sean individuos competentes, contribuyendo para que el aprendizaje sea significativo, teniendo como resultado una educación con alta calidad de desempeño escolar.

La guía virtual es formativa e informativa con opciones para el estudiante, docente y padre de familia, los cuales mediante un proceso minucioso y fácil de entender, podrán asimilar la situación que en el momento estén pasando, también tendrá la opción de un test de reflexión que le servirá para autoevaluarse y al finalizar la evaluación podrá tener los resultados con indicadores que le aconsejaran cual es la mejor recomendación de acuerdo al resultado.

En la producción de la presente investigación se estimó la aplicación de un CD interactivo multimedia como guía virtual con enfoque con criterio de desempeño afín a sus particularidades, siendo de propósito viable y factible que lleva plasmada la necesidad de reconocer problemas y proporcionar soluciones de forma metodológica, a través de documentos sustentados en textos 
Juanita I. Guevara-Burgos; Mónica A. Yépez-Mora; Silvia M. Placencia-Ibadango; Juana Y. Jiménez-Juanazo

legales y técnicos, necesarios para resolver las dificultades que presenta en la actualidad la Escuela fiscal "Enrique López Lazcano”, del cantón Santa Lucía.

\section{Materiales y Métodos.}

En la elaboración del proyecto se trataran varios tipos de investigación acorde a la necesidad establecidas en los pasos a seguir del estudio, técnicas y métodos que se logren utilizar en el mismo que acatará las estrategias de investigación. "En la Investigación se pretende analizar todos los temas con una gran profundidad" (Merino, Pintado \& Sánchez, 2010, p. 46). El abordaje de los temas de relevancia es importante para el sustento de la investigación.

Los estudios descritos por lo general están basados en las investigaciones correlacionales, los mismos que a su vez suministran información para producir estudios explicativos que forman y dan sentido de entendimiento altamente estructurados.

Las indagaciones efectuadas en un campo de conocimiento específico pueden contener tipologías de estudio en las diferentes etapas de su desarrollo. "Los estudios descriptivos buscan especificar propiedades importantes de personas grupos y comunidades o cualquier otro fenómeno que sea sometido a análisis (Henández-Sampieri, Fernández, \& Baptistas, 2006). Una investigación puede comenzar como exploratoria, luego ser descriptiva y correlacionar y por último como explicativa.

El CD interactivo multimedia fue desarrollado con el programa AutoPlay Media Studio 8, programa diseñado para crear AutoRuns, Auto arranque, capacidad de ejecutar una acción determinada de varios sistemas operativos al insertar un medio extraíble, ya sean memorias flash, CD o DVD y ejecutarlos en cualquier ordenador. 
Brinda la facilidad de crear aplicaciones multimedia interactivas sin necesidad de tener conocimientos en programación, este programa permite insertar y combinar imágenes, textos, videos, música, flash, entre otras a través que pueden ser arrastradas hacia su interfaz gráfica, lo cual dan comienzo a la creación de programas y presentaciones multimedia interactivas trascurrido un corto periodo de tiempo.

Este programa está diseñado específicamente para crear una gama de productos autoejecutables de multimedia, como Pack de Utilidades, álbum de audio video e imágenes, gracias a las herramientas de fácil manejo que contiene, a su vez permite trabajar con diversos tipos de archivos desde extensión de imágenes, textos hasta de base de datos y audio videos.

El esquema y creación de la guía es necesaria y significativa para el perfeccionamiento de las actividades en el aula por parte de los docentes, como una fuente de información que domina datos alineados al empleo de estrategias metodológicas para mejorar el factor socio- afectivo en el aprendizaje de los estudiantes.

Es por ello el uso de esta guía virtual propone la uso de procedimientos, objetivos y lapso de tiempo que debe emplear para cumplir cada actividad propuesta por el docente, a su vez que los estudiantes asimilen de una forma amena y divertida a seguir los pasos de la guía virtual. (Elorza, 2004) lo define como:

Un material que orienta al estudio de la asignatura para favorecer el trabajo autónomo. Presenta un plan o marco para el desarrollo de la Unidad, un calendario que facilita su organización en sesiones de trabajo, la enumeración de los recursos y materiales disponibles y las actividades a desarrollar por los estudiantes. Se debe justificar y motivar a los estudiantes para su uso. (p. 15). 
Una guía es un material suplementario que usan los docentes para facilitar la enseñanza dentro y fuera del aula, con la finalidad de fortalecer un determinado aprendizaje, contienen un método de trabajo para ser usado e incorporado en las planificaciones diarias del docente. Cabe recalcar que las relaciones docente - estudiante es directamente participativa, debido a esta relación se consiente el cambio de conocimientos entre la interacción que se mantiene.

El diseño de un CD Interactivo Multimedia como Guía virtual con enfoque con criterio de desempeño, ayudara a mejorar de las actividades escolares de los estudiantes del cuarto grado de educación general básica, de la Escuela Fiscal "Enrique López Lazcano" con el propósito de orientar, motivar, reflexionar y estimular al estudiante por parte del docente.

\section{Factibilidad de su Aplicación}

La actual propuesta es factible, pues entre sus objetivos se considera el solucionar problemas relacionados con la calidad del aprendizaje significativo de acuerdo al factor familiar y social de los estudiantes del cuarto grado de educación general básica de la Escuela Fiscal "Enrique López Lazcano", la misma que distingue aceptación por parte del personal docente del plantel educativo al contribuir con la ejecución del mismo, en donde se realizó la investigación, de tal manera aportaron con material para el diseño del CD interactivo multimedia como guía virtual con enfoque con criterio de desempeño.

Esta propuesta se constituye como una herramienta innovadora esencial en proceso de enseñanza-aprendizaje de los educandos, ayudando al docente a impartir conocimientos de una manera diferente convirtiendo las actividades de aprendizaje en activas debido a la oportunidad de participación que ofrece. 


\section{Impacto Social}

La guía virtual contribuye al cambio positivo entre las relaciones sociales y afectivas entre los docentes, padres de familia y estudiantes del cuarto grado de educación general básica, la principal idea es concientizar acerca de la importancia de los factores sociales y afectivos en el desempeño escolar.

A su vez incentivar el compromiso de todos los actores frente a la comunidad educativa, de manera alimentar el autoestima de los niños sea parte de las actividades escolares con la ayuda de los elementos como la motivación, así mismo se incita a los padres a involucrarse en las actividades escolares dentro y fuera de la institución educativa; el compromiso será mutuo para mejorar el aprendizaje significativo de los estudiantes.

\section{Beneficiarios}

Mejorar y dinamizar el aprendizaje de los estudiantes de Cuarto grado de Educación General Básica de la Escuela Fiscal "Enrique López Lazcano“, del Cantón Santa Lucía, Provincia Guayas; siendo los beneficiarios directos de la guía, esta ayudará a optimizar y facilitar la enseñanza por parte de los docentes y representantes legales, también beneficiarios de la propuesta.

\section{Factibilidad Financiera}

La institución educativa cuenta con una zona suficiente para el desarrollo de cualquier actividad; la presente propuesta tiene factibilidad financiera para la implementación y ejecución de la misma, se cuenta con el financiamiento de las autoras del proyecto lo que significa que no generará costo alguno ni a docentes, ni a estudiantes. 
Juanita I. Guevara-Burgos; Mónica A. Yépez-Mora; Silvia M. Placencia-Ibadango; Juana Y. Jiménez-Juanazo

Factibilidad Técnica

El CD Interactivo Multimedia como guía virtual con enfoque con criterio de desempeño se centra en mejorar las relaciones sociales y afectivas de los niños a través de la motivación de los padres y docentes. Los padres desarrollaran instintivamente la capacidad del interés por ser parte de la enseñanza-aprendizaje de sus hijos.

Así mismo se incita a los docentes a la constante actualización tanto en conocimientos pedagógicos y técnicos donde se involucre la tecnología, ya que esta se ha convertido en parte esencial del desarrollo de todas las áreas científicas.

El resultado de las anteriores será la contribución de la guía virtual para con los niños, ya que se verán motivados en la realización de las actividades consiguiendo desarrollar a cabalidad sus destrezas cognitivas e integrales lo que partirá alcanzar la calidad del desempeño escolar estimada.

\section{Factibilidad de Recursos Humanos}

Para la preparación del CD Interactivo Multimedia como guía virtual con enfoque con criterio de desempeño, intercedieron muchas personas entre ellos docentes, directivos y representantes legales de la Escuela Fiscal “Enrique López Lazcano”, quienes opinaron que tienen gran expectativa con el uso de esta herramienta.

\section{Estrategias Didácticas para Mejorar el Desempeño Escolar o Académico}

Los estudiantes viven en profundas metamorfosis de la estructura económica y social. Los efectos de la concentración de riquezas y el incremento de las desigualdades sociales presumen cambios en la interacción y en los modos de socialización dentro y entre partes sociales. 
En estos escenarios socioculturales, la educación se enfrenta a nuevos desafíos y tensiones sin precedentes. Reflexionamos que la exploración pedagógica debe contribuir a interrogar, cuestionar y comprender los factores que configuran el contexto actual desde una dimensión sociohistórica con una intención política tendiente a construir propuestas superiores. (Tenutto, 2006) afirma que:

La motivación son todas las necesidades del ser humano que abarcan un plano superior, que origina complejidad en su satisfacción. El impulso cognoscitivo es suficientemente potencial como para ser de suma importancia e inherente al mismo; está orientado hacia el sentido de que el aprendizaje exitoso constituye una gran recompensa a lo exterior. (p. 34)

Las dificultades emocionales y la conducta de los estudiantes constituyen un serio problema tanto para la educación y su entorno, los padres cuyos hijos no logran en el colegio un desempeño acorde con sus esfuerzos y expectativa; presentando dificultades emocionales, de aprendizaje y conducta en su desarrollo cognitivo, sin que nadie les preste la atención debida en su etapa escolar.

La carestía que tienen los estudiantes de ser motivados al estudio para que producirse de manera satisfactoria para el estudiante, docentes, padres y representantes es construyendo espacios que permitan ofrecer una visión constituida de lo que se desea cultivarse, para aportar la adquisición individual de aprendizajes significativos incluir mecanismos motivacionales y establecer premisas para lograr el fin de la educación.

\section{Fundamentación Tecnológica}

Conocer todo lo que nos rodea es llegar al irse a fondo de las cosas naturales y básicas que se requieren para realizar nuestras metas, se convierte en el punto básico donde se conoce como personas y corregimos algunas faltas que poseemos; con el adelanto de las tecnologías, ahora existen 
más conocimientos técnicos, establecidos científicamente, que admiten diseñar crean bienes y servicios que proporcionan la adaptación al medio ambiente satisfaciendo las necesidades esenciales de las personas.

La tecnología internamente en los demás campos de conocimiento, poseen múltiples bases y variadas la cual recoge contribuciones en las diversas ciencias y disciplinas a la hora de buscar soporte tecnológico que favorezca a lograr su fin. "En la Tecnología Educativa se insertan diversas corrientes científicas que van desde la física y la ingeniería hasta la psicología y la pedagogía, sin olvidarnos de la teoría de la comunicación" (Cabero Almenara, 2010). Desde sus inicios la tecnología ha sido de gran ayuda para el desarrollo de otras áreas, como la científica, la investigación y la técnica.

El uso de las TIC se están implementando favorablemente en las aulas, anteriormente las escuelas se restringían utilizarla, en la actualidad son las diferentes herramientas y medios que invaden partes fundamentales en el progreso social y su ejecución favorece el proceso de enseñanza aprendizaje.

\section{Conclusiones.}

El CD interactivo multimedia como guía virtual con enfoque y criterio de desempeño busca fortalecer los lazos afectivos, concientizar a los padres de familia y docentes la importancia de motivar a los niños para el desarrollo de sus habilidades, buscando mejorar el desempeño escolar no tan solo de un educando, sino del aula de clases.

Se considera al CD como recurso tecnológico empleado en la metodología aplicada en el aula de clases, también puede ser empleado como guía de capacitación por parte de los docentes hacia los padres de familia con la finalidad de despejar dudas, inquietudes acerca de las situaciones 
que aqueja a la actual sociedad, para de esta manera prepararse para la aceptación de nuevas ideologías, capaces de solucionar en unión familiar los problemas que se presenten en un futuro.

Esta propuesta es un diseño de un CD interactivo multimedia como guía virtual con enfoque y criterio de desempeño, que se convertirá en un apoyo para el docente originando, intensificando e impulsando a los estudiantes; extendiendo técnicas para mejorar el proceso de enseñanza aprendizaje, él objetivo será desarrollar el factor socio- afectivo en el nivel cognitivo en el aula de clases y corregir el desempeño de sus estudiantes.

Esta guía virtual se utilizara en la Escuela Fiscal "Enrique López Lazcano” del Cantón Santa Lucía y sus únicos beneficiarios directos son los estudiantes de la institución educativa. Los recursos a utilizarse para la realización de esta propuesta son: recursos Humanos, técnicos, tecnológicos y materiales. Durante la ejecución, se efectuará la evaluación, asistencia y la intervención activa de la información brindada; una vez terminada la realización de las actividades, se procederá a evaluar de manera sumativa a los integrantes de este proceso educativo.

El CD interactivo multimedia como guía virtual es de relevancia para la institución por los beneficios que brinda, debido a que es una estrategia metodológica innovadora de llegar a los docentes y padres de familia, siendo de gran utilidad por los problemas sociales actuales, ya que se resaltan factores esenciales como los sociales y afectivos que están involucrados directamente en el desempeño escolar de los niños.

Con la ejecución de la guía didáctica diseñada para los educandos del cuarto grado de educación general básica en la escuela fiscal "Enrique López Lazcano" se lograra desarrollar en forma correcta las diversas estrategias metodológicas innovadoras lo que evitara trabajar en forma 
improvisada, dejando a un lado el análisis autocritico planteados y resolver dificultades en cada una de las destrezas impartidas por los docentes.

\section{Recomendaciones.}

Para la debida utilización del CD Interactivo Multimedia como Guía Virtual con enfoque con criterio de desempeño es aconsejable considerar las siguientes recomendaciones:

El desarrollo e implementación del CD Interactivo multimedia como Guía Virtual se realizará con el objetivo de incentivar en la trilogía educativa la creación y participación del dialogo entre los estudiantes, siendo el docente quien guiara la actividad, lo que servirá como formación personal ante el reto que trae consigo la sociedad cambiante ya que desarrollaran la capacidad crítica y autocrítica.

Los docentes deben capacitarse constantemente con la finalidad de actualizar sus conocimientos y de esta manera ellos puedan preparar nuevas estrategias y aplicar otras metodologías que involucre a los representantes legales y de esta manera colaborar en la enseñanza aprendizaje de los estudiantes.

Los docentes que imparten clases en las instituciones fiscales y particulares deberían trabajar con el CD interactivo multimedia como guía virtual con la finalidad de crear un ambiente propicio para el interaprendizaje, desarrollando cada uno de los factores que influyen en la educación de los estudiantes y de esta manera lograr la calidad del desempeño escolar.

Las docentes deben compartir con los representantes legales parte de la información que sea recibida en las capacitaciones de actualización en las que sean partícipes, de esta manera ambos 
Diseño de un cd interactivo multimedia como guía virtual con enfoque y criterio de desempeño

tendrán la misma información con la que puedan ayudar al estudiante a desarrollar mejor sus aptitudes y capacidades.

\section{Bibliografía.}

Cabero Almenara, J. (2010). Los retos de la integración de las TICs en los procesos educativos. Límites y posibilidades. Revista Perspectiva Educacional, 49(1), 32-61.

Codina, L. (2004). Jornades Catalanes d’Informació i Documentació 9. Un espai de reunió, dediàleg, de participació. Evaluación de calidad en sitios web: proyectos de estudios sectoriales y realización de auditorías. Barcelona.

Elorza, G. (2004). Pequeños Creativos. Bogotá: Cultural Internacional.

Estevez Lopez, E. (2005). Violencia, victimización y rechazo escolar en la adolescencia. Valencia: Universitat de Valencia.

González García, J. (2015). Criterios para el diseño de materiales multimedia educativos. Interamerican Journal of Psychology, 49(1), 139-152.

Henández-Sampieri, R., Fernández, C., \& Baptistas, L. (2006). Metodología de la investigacioón (5 ed.). México: Mc Graw-Hill.

Marqués, P. (2000). Nuevos instrumentos para la catalogación, evaluación y uso contextualizado de espacios web de interés educativo. Revista RITE, 199-209.

Tenutto, M. (2006). Los significados otorgados al "constructivismo" por los profesores de Profesorados. Revista de Nuevas Tecnologías y Sociedad, 1-11.

Verschueren, K., \& Marcoen, A. (2002). Perceptions of self and relationship with parents in aggressive and nonaggressive rejected children. Journal of School Psychology, 40(1), 501-522. 